Capítulo 2

\title{
ENVEJECIMIENTO Y VEJEZ: DEL CONCEPTO Y LA TEORÍA A LA FUNCIONALIDAD DEL ADULTO MAYOR
}

Yisel Pinillos Patiño

María Victoria Quintero Cruz

\section{APROXIMACIÓN CONCEPTUAL DE LA VEJEZ Y EL ENVEJECIMIENTO}

El término vejez tiene su origen en el latín veclus, vetulus, que significa persona de mucha edad. Sobre este tema siempre han existido diferentes posturas que van desde las apreciaciones negativas, como es el caso de Aristóteles quien en su tiempo señaló que la senectud es sinónimo de deterioro y ruina y Séneca la catalogó como una enfermedad incurable; en la otra perspectiva se encuentran los postulados de Platón y Cicerón quienes plantean que con la vejez se dominan las pasiones, y que el viejo es respetado en tanto mantenga su autoridad y respeto sobre los suyos. Todas estas posturas filosóficas han servido como base para la conceptualización social de la vejez a lo largo de la historia del hombre (1).

Para establecer la edad exacta de una persona es preciso tener en cuenta consideraciones cronológicas, fisiológicas, psicológicas y sociales; la edad cronológica se determina por el hecho de haber cumplido un determinado número de años luego del nacimiento, por lo tanto la edad constituye un dato importante pero no determina la condición de una persona. Son diversos los aportes gerontoló- 
gicos que han emitido médicos y filósofos para el desarrollo de este concepto. Para la escuela hipocrática la vejez iniciaba después de los 50 años de edad y era entendida como el desequilibrio de los humores a partir del cual se explicaba la presencia de las enfermedades. Pitágoras además realizó una aproximación filosófica de la vejez con las estaciones climatológicas determinando que esta corresponde con el invierno y se inicia a los 60 años de edad; Galeno por su parte distinguió tres etapas: vejez incipiente (60-70 años en el hombre y 50-60 años para la mujer), vejez confirmada (hasta los 85 años en ambos sexos) y decrepitud (después de los 85 años). Actualmente la preocupación por el envejecimiento se acrecienta en la medida en que el número de personas mayores aumenta a nivel poblacional y aunque en general se acepta el hecho de que cada uno envejece a una edad diferente y que la edad no es criterio suficiente para delimitarla, los 60 años de edad ha sido establecido para marcar el límite entre la madurez y la vejez $(2,3,4)$.

La vejez es un proceso complejo y fascinante que todo ser humano experimenta; la sociedad tiende a definirla en términos de edad cronológica para conveniencias estadísticas y establece demarcaciones para cada una de las etapas de la vida, entre tanto que existen sociedades en las que la vejez está determinada por las condiciones mentales y físicas más que por las condiciones cronológicas; sin embargo, la vejez no implica el fin de un tiempo ni el ingreso a una etapa donde todo termina y aunque en la vejez se evidencia pérdida de algunas capacidades físicas para adaptarse a los factores que tienen influencia sobre este proceso, es preciso que el individuo continúe su integración a la sociedad tal y como sucede con las otras etapas del ciclo vital $(4,1)$.

El envejecimiento de los órganos y tejidos, los cambios progresivos del paso del tiempo sobre la condición física de la persona y 
la consecuente interferencia para el desarrollo autónomo de las actividades de la vida diaria, hace referencia al criterio fisiológico o biológico que permite determinar la edad del ser humano y está mediado por factores ambientales y rasgos genéticos individuales (1). Otro criterio es la edad psíquica o subjetiva, en la que tienen importante influencia los acontecimientos de vida de cada individuo, pues permiten aprender la reacción frente a ellos según la personalidad y experiencias aprendidas con anterioridad; tiene en cuenta la capacidad de aceptarse a sí mismo y de ajustarse a los diferentes entornos en los cuales se desenvuelve la persona. Entre tanto, el aspecto social permite determinar la edad tomando en cuenta el rol individual que desempeña en la sociedad, que varía de acuerdo con las necesidades económicas y políticas, los tiempos y las circunstancias del momento sin conocer la capacidad resolutiva del individuo. Este aspecto se encuentra ligado con el criterio económico ya que llega un punto de la vida en que la persona deja de generar recursos económicos, pierde la capacidad para producir bienes y se torna económicamente inactivo $(4,2)$.

De acuerdo con lo anterior, el concepto de vejez de una persona depende de aspectos culturales; en las antiguas civilizaciones, cuando a los más ancianos se les hacía más difícil sobrevivir se optaba por abandonarlos debido a la lucha constante con la naturaleza para la supervivencia. Sin embargo las sociedades continúan con su evolución, y en la Grecia arcaica, vejez era sinónimo de sabiduría, garantizador de la tradición, conocedor del pasado y de gran experiencia de vida; entre tanto en la Grecia clásica, Roma Imperial y el Renacimiento, cuando la sociedad se desarrollaba en torno al ideal estético y del culto al cuerpo, la vejez era determinada por la pérdida de las cualidades propias de la juventud (belleza, fuerza física, agilidad, vitalidad, entre otros); en la Edad Media, momento de guerras, la vejez fue vista de manera positiva, y actualmente 
se considera como una etapa en la que el individuo pasa de transformar la realidad a ser transformado por ella (2).

El valor trascendental de la vejez perduró en la sociedad hasta el Renacimiento, representado en la gerontocracia predominante en esta época; sin embargo luego de la Segunda Guerra Mundial se instaura la postura del rejuvenecimiento de las estructuras sociales alejando a los ancianos de las cercanías del poder. A mediados del siglo XX, las personas mayores que representaban el componente de autoridad y respeto en la familia fueron perdiendo dicha posición debido a los enfrentamientos mundiales generacionales, relegando esta figura a un círculo cada vez más cerrado a tal punto de perderse su credibilidad, convirtiéndolo en un fenómeno social que dificulta la cobertura de sus necesidades por parte de los individuos de su entorno; hecho que se refuerza con el advenimiento de las tecnologías y el desarrollo del internet afectando tanto a las sociedades desarrolladas como a las menos desarrolladas y que socava la reputación de este grupo de personas (3).

El envejecimiento es considerado como un proceso multifactorial, normal, que conjuga una serie de transformaciones, cambios y/o alteraciones neurobiológicas estructurales, funcionales y químicas relacionadas o mediadas directamente por factores ambientales, psicológicos y socioculturales tales como la calidad y estilo de vida, la dieta, el sedentarismo, el ejercicio y que generan dificultades en el desarrollo de las actividades de la vida diaria así como restricciones en su participación $(5,6,7)$; por lo tanto se considera que en la vejez se enfrentan retos y adaptaciones debido a los cambios graduales de las condiciones físicas y mentales del individuo en el transcurrir del ciclo vital y las poblaciones envejecen cuanto mayor número de personas envejecidas existen (8). Por lo tanto estos planteamientos permiten identificar que la vejez es una etapa del ciclo vital irrever- 
sible y que inicia desde el momento del nacimiento, entre tanto que el envejecimiento es ese fenómeno o proceso que sufre todo ser humano desde su concepción y que se hace evidente con el incremento de personas adultas en la sociedad.

\section{Etapas del envejecimiento y sus cambios fisiológicos}

Se estima que el ser humano puede vivir entre 110 y 120 años y que alcanza la madurez biológica alrededor de los 25 y 30 años de edad; sin embargo para los países desarrollados se considera adulto mayor a las personas de 65 años en adelante, mientras que para los países en desarrollo este grupo lo integran quienes tienen 60 años y más $(6,9,10,11)$.

En el transcurrir de la vida el ser humano pasa por diferentes etapas, las cuales conforman el denominado ciclo vital; este supone una serie de cambios biológicos, psicológicos y químicos que al llegar al clímax de su desarrollo genera un proceso de involución en las funciones sistémicas; todo ello ocurre en unas fases estrechamente ligadas entre sí denominadas niñez, adolescencia, adultez y vejez (12).

El envejecimiento, la última etapa del ciclo vital puede ser tardío o precoz, fisiológico o patológico y consta de una serie de etapas intermedias establecidas en función de criterios biológicos: la presenilidad, es el momento donde se evidencian las primeras transformaciones propias del fenómeno de envejecimiento tal como la desaparición de las funciones reproductivas sin ser una característica precisa ya que la menopausia y la impotencia no siempre concuerdan con los demás signos seniles, vejez propiamente dicha o vejez tardía corresponde a la presencia de las alteraciones 
biológicas, parenquimatosas y glandulares, la senectud es la fase en la que se continúan los procesos característicos de la vejez sin llegar a la falta de vitalidad, y la última etapa denominada decrepitud senil en la que se observa disfunción extrema de los sistemas y pérdida de la capacidad funcional autónoma por la presencia de afecciones ocurridas en otras etapas de la vida o degeneración de algunos sistemas. Según las edades esta población se organizaría en tres grupos: los de baja senilidad, en este grupo se encuentran las personas con edades comprendidas entre 60 y 75 años de edad; senilidad, se encuentra conformado por las personas de 76 a 85 años, y en un último grupo, alta senilidad se encontrarán los adultos mayores de 85 años de edad (2).

Con el paso del tiempo el cuerpo humano va experimentando cambios que se expresan en la dificultad para realizar de manera autónoma sus actividades de la vida diaria debido a las limitaciones funcionales acaecidas por las deficiencias sistémicas que se conjugan en esta etapa del ciclo vital repercutiendo en la independencia y la calidad de vida del adulto mayor; así el envejecimiento se asocia de manera general con el enlentecimiento de las funciones por lo cual todas aquellas tareas que dependen del tiempo decaen durante este proceso; sin embargo estos cambios dependen de la edad de inicio, el sexo, las estructuras comprometidas y el estilo de vida $(13,14)$.

Aunque los cambios durante el envejecimiento ocurren en todos las estructuras corporales, a continuación se describen los que suceden en algunos sistemas que por sus implicaciones pueden afectar la funcionalidad en la vejez. Así mismo se mencionan algunos cambios en la esfera social que sin duda repercuten en el bienestar del adulto mayor. 


\section{Sistema cardiovascular}

Los cambios que ocurren en la pared vascular traen como consecuencia el endurecimiento de las arterias, una de las principales características del envejecimiento de este sistema.

Las fibras elásticas de los vasos sanguíneos sufren degeneración, adelgazamiento, ramificación y fractura; así mismo aumentan la cantidad de fibras colágenas que se traduce en esclerosis, el entrecruzamiento de estas fibras, y la arterioesclerosis como consecuencia de la microcalcificación en la túnica media de la pared vascular. También se observa menor función vasodilatadora dependiente del endotelio. Otro de los cambios vasculares que ocurren con el envejecimiento es el aumento de la rigidez de las arterias de conducción y la resistencia periférica debido a la hipertrofia de las arterias de resistencia caracterizada por engrosamiento de la pared y reducción del lumen. Todo lo anterior se traduce en aumento de la presión arterial, principalmente de la sistólica la cual aumenta progresivamente con la edad (15).

A nivel cardiaco, el envejecimiento disminuye la distensibilidad y la respuesta fisiológica del corazón al ejercicio, así como aumento de la rigidez de la pared ventricular, sin embargo no está claro a qué edad ocurren estos cambios. Estudios han demostrado que la actividad física regular durante la transición entre la juventud y la edad media, puede retardar y atenuar estos cambios (16).

\section{Envejecimiento muscular}

Con el envejecimiento el músculo esquelético sufre disminución de la masa magra, siendo infiltrado por tejido graso y conectivo; hay disminución de las fibras musculares tipo II, desarreglo de 
las miofibrillas, disminución de las unidades motoras, y disminución del flujo sanguíneo, además acumulación de lipofuccina y poca formación de miofibrillas. Estos cambios sin duda afectan la capacidad muscular para generar fuerza. Todas estas alteraciones del músculo esquelético en la vejez pueden generar sarcopenia, la cual se asocia con morbilidad y mortalidad en los adultos mayores, así como a altos costos a nivel sanitario (15).

\section{Envejecimiento cerebral}

Con el envejecimiento el cerebro disminuye su volumen, sin embargo esto no se debe a la pérdida generalizada de neuronas corticales, ni de la arborización detrítica como llegó a pensarse a mediados del siglo pasado. Estudios actuales han determinado que esta pérdida ocurre en regiones específicas del cerebro, por ejemplo la corteza prefrontal, lo cual se correlaciona con el deterioro de la función cognitiva. Los cambios cognitivos ocurridos con el envejecimiento cobran gran relevancia a nivel biomédico debido a su frecuencia y asociación con discapacidad. Hay menor capacidad de atención, memoria de trabajo y trastornos motores, presentando estos cambios gran variabilidad entre los sujetos. (15).

\section{Sistema renal}

Estudios han mostrado que existe asociación entre los cambios estructurales y el declive de la función renal con el envejecimiento, sin embargo no hay evidencia sobre los cambios específicos del envejecimiento, ni hasta donde la disminución de la función renal es fisiológica o consecuencia de alguna otra condición de salud como enfermedad cardiovascular, diabetes, etc. 
Entre los cambios estructurales a nivel renal se encuentran adelgazamiento de la corteza renal, esclerosis de las arterias glomerulares y engrosamiento de la membrana basal glomerular, los cuales se relacionan con disminución de la velocidad de filtración, menor capacidad para concentrar orina y menor hidroxilación de la vitamina $\mathrm{D}$ (15).

\section{Cambios en el metabolismo de la glucosa}

Los cambios en la composición corporal de menor masa muscular y aumento de grasa visceral traen repercusiones negativas en el perfil metabólico de los adultos mayores, lo cual ha recibido el nombre de obesidad sarcopénica, siendo un predictor de síndrome metabólico. Se ha demostrado que el tejido adiposo visceral influye en la resistencia insulínica, participando en la producción de mediadores inflamatorios como TNF- $\alpha$ e IL-6 (15).

Los cambios en la homeostasis de la glucosa en el adulto mayor pueden contribuir a alterar el hambre y la saciedad. Así mismo durante el envejecimiento ocurre disminución de la replicación de las células beta y por consiguiente de la producción de insulina. En la vejez ocurre una disminución de la contrarregulación del metabolismo de la glucosa que se evidencia como menor respuesta del glucagón a la hipoglicemia y retraso a la recuperación de esta (17).

\section{Cambios sociales}

Cambios en el rol individual: como individuo único, como integrante de un grupo familiar y como persona capaz de afrontar las pérdidas.

Cambio de rol en la comunidad: las costumbres, estilos de vida y las concepciones de la vida generan grandes diferencias lo que le hace 
a la persona mayor cambiar su rol social distanciándose del resto de las generaciones.

Cambios en el rol laboral: un gran cambio que se da por el momento de la jubilación limitándose trascendentalmente las relaciones sociales al momento de abandonar el espacio de trabajo así como los recursos económicos (18).

Sin embargo, los cambios cognitivos y de comportamiento resultan de las múltiples alteraciones biológicas que las desencadenan y la limitación del estado funcional se relaciona con enfermedades producto de hábitos inadecuados en el desarrollo de su ciclo de vida (6).

\section{Teorías del envejecimiento}

Durante el envejecimiento se evidencian cambios moleculares que se explican a partir de las teorías, lo que pareciera un deterioro programado generado por una cascada de eventos moleculares y celulares es inevitable y direccionado por unas reglas biológicas que explican el desgate generado por el constante sometimiento a una determinada función; todo ello se entiende que es favorecido por procesos primarios ocurridos con el inicio del envejecimiento del

40 individuo y procesos secundarios generados por el estilo de vida, la ingestión de dietas calóricas y la actividad física (6).

Bertrand Strehler, citado por González, describe el envejecimiento como un proceso deletéreo (se pierden funciones fisiológicas), progresivo (esas pérdidas son graduales), intrínseco (son propias de cada persona) y universal (se producen en los miembros de una misma especie una vez que llega el momento), como evidencia de la relación entre la información genética del individuo y el ambiente en el cual se desenvuelve (19). Este proceso complejo y dinámico 
es posible explicarlo solo a partir de las teorías que confirman la ocurrencia del fenómeno como producto de los daños celulares y tisulares al fallar la homeostasis entre genes de mantenimiento y genes de reparación mediados por los factores ambientales, dando como resultado el deterioro progresivo de la salud y la calidad de vida del individuo $(2,20)$.

La ciencia propone diversas teorías sobre la causa del envejecimiento, las cuales pueden disponerse en 3 grupos: Teorías Biológicas (Teorías Estocásticas que explican el proceso de envejecimiento como consecuencia de la aleatoriedad y la acumulación de agresiones contra el organismo y las Teorías Deterministas o No Estocásticas que argumentan el fenómeno del envejecimiento como un proceso programado y dirigido), Teorías Psicológicas y Teorías Sociales.

Biológicamente el ser humano comienzan a envejecer desde el mismo nacimiento, las situaciones y el medio en el cual se desarrolla solo aceleran este proceso. Sin embargo en la actualidad son muchas las teorías que intentan explicar las causas del envejecimiento, pero esta no solo debe explicar el mecanismo de desarrollo del ser vivo y su consecuente muerte sino las variaciones en el transcurso del tiempo y los cambios que se dan en los diferentes elementos que componen el cuerpo.

\section{TEORÍAS BIOLÓGICAS}

Teorías Estocásticas: consideran al genoma como el principal causante del fenómeno y junto a ello incluyen fenómenos del ambiente que afectan la homeostasis celular. 
Teoría de Disfuncionamiento del Sistema Inmunológico: partiendo del hecho de que el sistema inmunológico es el medio de defensa que utiliza el cuerpo humano contra toda sustancia del medio externo que pretenda ingresar al mismo, utilizando para ello la fagocitosis, la lisis o destrucción de la célula infectada, la producción de anticuerpos específicos por medio de las células del sistema inmune como los monocitos, macrófagos, los polimorfonucleares, linfocitos B y linfocitos $\mathrm{T}$, la teoría del sistema inmunológico del envejecimiento se fundamenta en el supuesto de que con la edad la producción de anticuerpos se ve disminuida, por lo cual la capacidad para enfrentar agentes agresores está limitada y de alguna manera el cuerpo reconoce algunas partes de sí como invasores exógenos y los ataca (19). Aunque esta teoría por sí sola no explica todas las observaciones del envejecimiento, retardar este proceso implica interferir la senectud inmunológica lo cual protege al adulto mayor de cualquier proceso viral común.

Teoría de Envejecimiento Celular: propuesta por Child, supone que el envejecimiento ocurre como consecuencia de la muerte de un número considerable de células en el cuerpo; se fundamenta en el límite que tienen las células de dividirse mediante mitosis un número limitado de veces durante su existencia, inclusive aquellas células de recambio rápido (4). Con cada división celular los telómeros disminuyen su tamaño hasta que se hace imposible cualquier otro proceso mitótico llevando a la célula hasta la muerte al dejar de dividirse; sin embargo existen otras causas que explican la muerte de las células:

- Teoría del desgaste natural: explica el envejecimiento a partir de la acumulación de daños generados por el deterioro de las actividades bioquímicas normales con el consecuente desgaste de las células y tejidos corporales donde se ve afectada principalmente la mitocondria y por ende la actividad celular. 
- Teoría de la acumulación de productos de desecho: Sheldrake propuso que: "el envejecimiento celular se puede explicar en términos de la acumulación de la ruptura de productos citoplásmicos, algunos de los cuales pueden ser perjudiciales para la célula; la única manera en que las células podrían evitar su mortalidad inevitable sería creciendo y dividiéndose, diluyendo la ruptura acumulada de productos" (21). Esta teoría se fundamenta en el hecho de que la célula produce sustancias de desechos que no se pueden transportar ni destruir y se convierten en perjudiciales para la división o reproducción celular, quedando debilitado el funcionamiento normal de la célula a causa de la acumulación excesiva de productos emanados de las funciones celulares (19).

- Teoría de la autointoxicación: la acumulación de toxinas originadas por la flora intestinal explica el envejecimiento; como solución Metchhnikov proponente de esta teoría, aconsejaba consumir yogurt búlgaro, cuyas bacterias lactófiras desplazarían a las nocivas.

- Teoría del envejecimiento natural.

- Teoría del entrecruzamiento.

- Teoría de errores en la síntesis de proteínas.

- Teoría bioquímica o de los radicales libres.

- Teoría de las modificaciones del sistema endocrino.

- Teorías genéticas.

- Teorías capilorosopatía senil. 


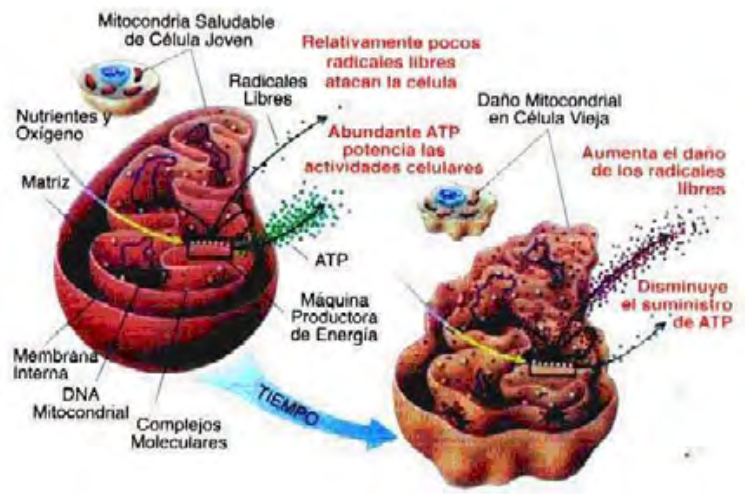

Figura 1

Fuente: Imagen tomada de la página web Alucina Medicina. Disponible en: http://alucinamedicina.com/tag/radicales-libres/

\section{TEORÍAS PSICOLÓGICAS}

Teoría del desarrollo: Erikson 1950. Plantea la etapa de la vejez desde los 65 años en adelante, contemplando factores individuales y culturales. Su teoría menciona que la crisis esencial es integridad vs. desesperación. Las principales virtudes son la prudencia y la sabiduría (22).

Teoría de la actividad: Fue propuesta por Havighurs. Se basa en la importancia del mantenimiento de los roles y las acciones y de las ocupaciones sociales para mantener una vejez satisfactoria. Los

44 defensores de esta teoría sostienen que la vejez es una extensión de la vida media y que podría abolirse manteniéndose activo. La familiaridad y la frecuencia de la actividad refuerzan el autoconcepto de sí mismo teniendo gran importancia la voluntad o no de la persona y la posibilidad de mantener la actividad (23).

Teoría de la continuidad: Esta teoría postula que los rasgos de personalidad de un individuo determinan las relaciones existentes entre la satisfacción por la vida y la actividad realizada, los rasgos de la personalidad se arraigan y evidencian según se envejece. El paso a 
la vejez es una prolongación de experiencias, proyectos y hábitos de la vida. La personalidad y sistema de valores se mantienen prácticamente intactos (23).

Teoría del ciclo vital: Sostiene que los acontecimientos, decisiones y conductas de la persona en etapas previas a la vejez determinan la situación y la posición social vivida como adulto mayor.

Esta teoría establece la noción de que la vejez es una etapa más del ciclo de vida de la persona, y como tal tiene sus propias normas, roles, expectativas y estatus. Se considera como parte de un proceso y no la etapa terminal de la vida (24).

Teoría de la selectividad socioemocional: Fue propuesta por Cartensen en 1998, postula que las relaciones interpersonales solo son provechosas para los ancianos cuando son de buena calidad, es decir que favorecen un buen contacto emocional. El bienestar general y el buen envejecimiento se pueden lograr con la satisfacción de las necesidades psicológicas fundamentales (25).

\section{TEORÍAS SOCIALES}

Teoría de la desvinculación: Sus autores Cumming y Henry, la hacen ver como universal y aplicable a las personas en todas las culturas, aunque con variaciones en la forma y el momento en que se producen. Rechaza la actividad en edades avanzadas y establece que hay una desvinculación social del adulto mayor, resultante de la menor interacción entre éste y el sistema social al que pertenece (23).

Teoría de la subcultura: La edad o el agrupamiento por edades conducen inevitablemente a la formación de una subcultura, la cual dirige y define la conducta de sus miembros. Desde esta mirada la 
sociedad estaría forzando a los adultos mayores a conformar una minoría, es decir una subcultura, que fácilmente se puede confundir con marginalidad, clasificándolos como un grupo caracterizado por la pobreza, aislamiento social, inmovilidad física y social, entre otros.

La actividad social de los adultos mayores, como la de los demás grupos etarios, está determinada por tres factores: La salud, los ingresos económicos y las relaciones interpersonales con que cuenta (24).

Teoría de la modernización: Busca en el pasado explicar el sentido actual del envejecimiento; los cambios sociales causados por la modernización confluyen en una disminución de la valoración social de la vejez.

Esta teoría parece no tener argumentos muy sólidos ya que se parcializa a países occidentales, sin embargo se le abona que llamó a discusión la importancia de la familia y el trabajo en la conformación social de la vejez (24).

\section{REFLEXIONES FINALES}

46 Finalmente, es importante resaltar con relación a las teorías, que no existe una explicación única para el proceso de envejecimiento, por lo tanto se infiere que una teoría complementa a la otra para la comprensión de la fase final del curso de vida del ser humano.

\section{RFERENCIAS BIBLIOGRÁFICAS}

1. Cardona AD, Peláez E. Envejecimiento poblacional en el siglo XXI: oportunidades, retos y preocupaciones. Salud Uninorte Barranquilla (Col.) 2012;28(2):335-348. 
2. Rodríguez SL, García GM, García BM. Manual del técnico auxiliar de geriatría, Envejecimiento. España: Editorial Mad, S.L. Segunda Edición, Octubre 2003. Página: 16-22. Disponible en: http://books.google.es/books?hl=es\&lr=\&id=5VFKRFM$1 \mathrm{MXoC} \&$ oi $=$ fnd \&pg=PA38\&dq=teor\%C3\%ADas +del+envejecimiento\&ots $=$ wcoGAPQZZr\&sig=lnQWopG6FrWmqwi wrsbkgJpr3xs\#v=onepage\&q=teor\%C3\%ADas\%20del\%20 envejecimiento\&f $=$ false

3. Rodríguez DeVera, Bienvenida del Carmen. Lavejez, patrimonio inmaterial de la humanidad. Gerokomos 2008;19(2):33-35.

4. Alvarado A, Salazar A. Análisis del concepto de envejecimiento. Gerokomos. 2014;25(2):57-62.

5. Sarabia CC. Envejecimiento exitoso y calidad de vida. Su papel en las teorías del envejecimiento. Gerokomos 2009; 20(4):172-174.

6. Santos HF, Andrade MV, Bueno AO. Envelhecimento: um processo multifatorial. Psicologia em Estudo. 2009; 14(1):3-10.

7. Santos S. Concepções teórico-filosóficas sobre envelhecimento, velhice, idoso e enfermagem gerontogeriátrica. Rev. bras. enferm. 2010; 63(6):1035-1039.

8. Cárdenas JA, López DA. Resilencia en la vejez. Rev. salud pública. 2011; 13(3):528-540.

9. Ministerio de la Protección Social, República de Colombia. Política nacional de envejecimiento y vejez 2007-2019. Disponible en: http://www.minsalud.gov.co/Documentos\%20y\%20 Publicaciones/POL\%C3\%8DTICA\%20NACIONAL\%20DE\%20 ENVEJECIMIENTO\%20Y\%20VEJEZ.pdf

10. Organización de Naciones Unidas. Asamblea Mundial sobre envejecimiento: resolución 39/125. Viena, ONU; 1982.

11. Departamento Administrativo Nacional de Estadística. Estimaciones y proyecciones de población, Estimación y proyección de población nacional, departamental y municipal por sexo, 
grupos quinquenales de edad y edades simples de 0 a 26 años; 1985-2020. Disponible en: http://www.dane.gov.co/index. php?option=com_content\&view=article\&id=75\&Itemid $=72$

12. Martínez FA, Carmenate MM, María E. Díaz, Toledo E, Prado MC, Padrón R, Rodríguez L, Wong I, Moreno R, Moreno V. Estudios de Antropología Biológica. 2009;9(1):465-480.

13. Landinez PN, Contreras VK, Castro VA. Proceso de envejecimiento, ejercicio y fisioterapia. Revista Cubana de Salud Pública. 2012;38(4):562-580.

14. Ministerio de Sanidad, Política Social e Igualdad, Secretaría General de Política Social y Consumo, Instituto de Mayores y Servicios Sociales (IMSERSO). Tendencias demográficas actuales. Envejecimiento activo, Libro Blanco. 2011:página 33. Disponible en: http://www.imserso.es/imserso_01/envejecimiento_activo/libro_blanco/lbea_cap/index.htm

15. Salech F, Jara R, Michea L. Cambios fisiológicos asociados al envejecimiento. Rev. Med. Clin. Condes. 2012;23(1) 19-29.

16. Pemberthy C, Jaramillo-Gómez N, Velásquez C, Cardona-Vélez J, Contreras-Martínez H, Jaramillo-Restrepo V. Conceptos actuales sobre el envejecimiento y la enfermedad cardiovascular. Rev Colomb Cardiol. 2016;23(3):210-217.

17. Ortiz G, Árias-Merino E, Velázquez-Brizuela I, Pacheco-Moisés F, Flores-Alvarado L, Torres-Sánchez E, Cortés-Enríquez F, González-Renovato E, Ortiz-Velázquez I. Envejecimiento y metabolismo: cambios y regulación. Archivos latinoamericanos de nutrición. 2012; 62(3):249-257.

18. López E, Findling L, Lehner P, Mario S. Aspectos sociales del envejecimiento y los cuidados. En: Kornblit A, Camarotti A, Güelman M. X jornadas nacionales de debate interdisciplinario en salud y población. Buenos Aires: Teseopress.com; 2013:145-188.

19. González GJ. Teorías del envejecimiento. Tribuna del Investigador. 2010;11(1-2):42-66. 
20. López ME, Torres CN. Aspectos moleculares del envejecimiento. México: Secretaria de Salud, Instituto de Geriatría $1^{\mathrm{a}}$ Edición. 2012:42.

21. Pardo AG. Consideraciones generales sobre algunas teorías del envejecimiento. Rev Cubana Invest Biomed. 2003;22(1):58-67.

22. Erikson E. El ciclo vital. Argentina: Paidós, 1995.

23. Ortega, Albers, Pedrero, López en Casajús J, Rodriguez G. Ejercicios y salud en poblaciones especiales. EXERNET. 2011.

24. Superintendencia de Salud de Chile. Dependencia de los adultos mayores en Chile. 2008.

25. Vivaldi F, Barra E. Bienestar Psicológico, Apoyo Social Percibido y Percepción de Salud en Adultos Mayores. Terapia psicológica. 2012; 30(2):23-29.

\section{Cómo citar este artículo}

Pinillos Patiño Y, Quintero Cruz MV. Envejecimiento y vejez: del concepto y la teoría a la funcionalidad del adulto mayor. In Quintero Cruz MV, Pinillos Patiño Y, Herazo Beltrán AY, Vidarte Claros JA, Cardeño Sanmiguel GM, Morales Castro YR. Ejercicio físico para la condición física funcional en el adulto mayor: Estrategia de intervención. Barranquilla: Universidad Simón Bolívar; 2017. p. 31-49. 